\title{
Problems of Expressiveness in Geoaesthetics
}

\author{
Kwang Myung Kim \\ Department of Philosphy, Soongsil University, Seoul, South Korea \\ Email: kmkim@ssu.ac.kr
}

Received 5 September 2014; revised 28 September 2014; accepted 10 October 2014

Copyright (C) 2014 by author and Scientific Research Publishing Inc.

This work is licensed under the Creative Commons Attribution International License (CC BY).

http://creativecommons.org/licenses/by/4.0/

(c) (i) Open Access

\section{Abstract}

Facing in the prospect of geo-environmental activities like volcanic explosions, earthquakes, floods, landslides, subsidence issues, tsunamis, etc., we have to reconsider a sustainable harmony between human beings and nature. Approaching the reality of the changing patterns of the earth's surface and geological processes geoaesthetically will be helpful in establishing a more desirable relationship between human beings and nature. In this paper the author attempts to consider the meaning of expressiveness in relation to geoaesthetics, and further the author intends to reveal expressiveness through various phenomena of the earth. Expressiveness can evoke emotion as one experiences the aesthetic object. Empathy plays a role in drawing expression from expressiveness. One can find geoaesthetic expression through looking deeply into the expressiveness the earth presents. Earth itself is inanimate, but owing to its plentiful expressiveness it can restore the organic, animate world.

\section{Keywords}

\section{Geo-Environmental Problems, Expressiveness, Expression, Empathy, Geoaesthetics}

\section{Introduction}

Presented with geo-environmental problems at a critical moment in our history-volcanic explosions, erosion, flooding, landslides or mudslides, tsunamis, etc.—-we have to reconsider establishing a sustainable, harmonious relationship between human beings and nature. To escape such geo-environmental disasters we need to keep aesthetic, optimal distance and to contemplate present-day situations in safety. Approaching the changing nature of the earth's surface and geological processes geoaesthetically will be helpful in set ting up a more desirable relationship between human beings and nature ${ }^{1}$. Understanding aesthetic expressiveness in nature is especially useful for considering and recognizing the harmonious coexistence between human beings and nature. Research

${ }^{1}$ Earthsong (N.Y.: Phaidon 2008)—collaboration of photographer Bernhard Edmaier and geologist Angelika Jung-Hüttl provided me with informative insights. 
in aesthetics often seeks to explain the expressive qualities of artifacts in terms of expressive activity among human beings, including natural beings. In this study the author will consider the meaning of expressiveness in relation to geoaesthetics, and further, reveal the expressiveness through various phenomena of the earth's surface. In the end the author hopes we can find the natural order, in a word, the natural equilibrium by looking deeply into the meaning of expressiveness. Through the transition from extrinsic phenomena to intrinsic significance, the aesthetic character can be revealed through expressiveness.

We can observe the expressive qualities of various arts. Expressiveness is contained in the aesthetic object itself. To find and draw out this expressiveness in objects is the task of artistic expression ${ }^{2}$. Perceptual psychologist R. Arnheim (1904-2007) considered expression in relation to sensory perception. Expression appears outwardly as a result and a primary content of perceptual experiences. Mentality functions in response to sense observation. Arnheim does not advocate self-expression, because the method of self-expression plays down the function of the theme to be represented. Expression is localized in the object of representation. Expression is a key to understanding the meaning of art. An artistic medium is used in justifying something expressed ${ }^{3}$. According to M. Rader and B. Jessup we can use the term "expressiveness" for the content that is expressed, and "expression" for the act of expressing. Expressiveness is found in natural phenomena. Nature and the environment are replete with expressive qualities (Rader/Jessup, 1976: p. 41). Natural phenomena like "a steep rock, a willow tree, the colors of a sunset, the cracks in a wall, a tumbling leaf, a flowing fountain...have as much expression as the human body" (Arnheim, 1969: p. 433). Expressiveness is an inherent characteristic of a perceptual pattern. Expressiveness is the invisible character and can appear through expression as a visible pattern.

Generally speaking, empathy is an understanding of another person from inside by feeling together. Empathy plays a role in creating positive and active engagement in geoaesthetics. The expression of geological phenomena in experiencing the waves and lines of a shoreline or coastline is similar to experiencing the rhythmical streams of song. The optimal attitude of art appreciation in the beholder and listener is in finding expressiveness deeply rooted in the object. Coexisting harmony between human beings and nature is revealed in emotional expressiveness through the arts. Expression conveys emotion between subject and object. Experiencing the emotion brought by a perceptible object reveals its expressiveness. A work of art has an expressive dimension when it evokes an emotion. Now in turn the author will consider the meaning of expressiveness in relation to expression and empathy; expressiveness as a possibility of aesthetic expression in geoaesthetics; natural order, and equilibrium in geoaesthetical expressiveness; and the aesthetic expressiveness in geological phenomena.

\section{The Meaning of Expressiveness}

"Expressive" is related to expression and characterized by expression. Expressiveness has the quality of being expressive and it serves expression. Expressiveness contains everything which can be expressed. "Claims about expressiveness can also be claims about feelings evoked when people experience works of art or claims about the works of art" (Eaton, 1988: p. 31). Expressiveness can evoke emotion in experiencing the aesthetic object. To draw expression from expressiveness it is necessary to refer to the role of empathy. Empathy can evoke animate expression from inanimate expressiveness.

\subsection{The relation of Expressiveness to Expression}

The relation of expressiveness to expression is similar to the wholeness of an iceberg to the tip of an iceberg. The externally appearing expression and the internal hidden expressiveness seem to be metaphorically similar a glacial mass. Expression is oriented to the subject as an expresser; on the other hand expressiveness is oriented to the object as a thing to be expressed. Expression can be experienced as the result of expressiveness coming after the expressing activity. We can express our emotions by various means, like gestures, postures, facial figures, and other actions. These various means can be applied metaphorically and analogically to express geological phenomena. Geological phenomena are the facial expressions of the earth.

The relation between expression and what is expressed is not always as straightforward as the relationship between phenomenon and noumenon, like tears and grief, joy and smiles, etc. (Green, 2008: p. 104). Every work

\footnotetext{
${ }^{2}$ As John Dilworth pointed out, there are some different ways of interpretation on the artistic expression like ontological, epistemic, real, free virtual, etc. John Dilworth, “Artistic Expression as Interpretation”, British Journal of Aesthetics, Vol.44, No.1, Jan. 2004, pp. 10-28.

${ }^{3}$ Rudolf Arnheim, “The Priority of Expression,” The Journal of Aesthetics and Art Criticism, Vol.8, No.2, Dec. 1949, pp. 106-109. Interestingly, Arnheim's doctoral dissertation (1928) was a study of expression in human face and handwriting.
} 
of art may contain more or less the source of our emotions ${ }^{4}$. For this very reason through works of art we can develop deeper forms of emotional experience. These two factors of structure and emotional expression are correlated. "One theme binding together different forms of expression is the ability of the expressive behavior or artifact to enable in an appropriate observer knowledge of what it expresses. Expression makes something knowable to appropriate observers; making something knowable to appropriate observers, in turn, to show it; hence expression is a species of showing” (Green, 2008: p. 104). Expression as showing-how is related to showing-that as contents of expressiveness. Our dominant sense is vision, and it's the relational activity of showing and the shown.

Expressiveness can be objectively described through showing how. Peter Kivy's "contour theory" holds that music's "sonic 'shape' bears a structural analogy to the heard and seen manifestations of human emotional expression” (Kivy, 2002: p. 40; Green, 2008: p. 107). Generally we can refer to the shape or outline of an object as its contours. We can describe sonic shape, visual sensation, visual shape, etc. "A work's expressiveness is due either to its showing how an emotion, mood, or experience appears, or to its showing how an emotion, mood, or experience feels" (Green, 2008: p. 112). We can say a work's expressiveness is due to the appearance of emotion, mood, and experience. The expressiveness of artwork is related to appearance and feeling. The degree of appearance and the intensity of feeling are contained in the expressiveness of an object. Objective appearance and subjective feeling are two sides of the same coin.

An artwork that expresses an emotion in an expressive way is one that reveals something of what it is like to be in such an emotional state. Some people can agree that "art is possible and valuable because it involves human expressiveness" (Eaton, 1988: p. 23). Expression is "a relation between an artwork and an expresser, who is either the author or an imagined agent such as the implied author, a narrator or a character in the work" (Robinson, 2007: p. 36). According to Jenefer Robinson, "expressiveness as a relation between the expression and the audience to whom it communicates, depends on how effectively the artwork reveals to a suitable beholder what that emotion is like” (Robinson, 2007: p. 36). A thing is derived from thingness, and thingness gives essential character to a thing. Thingness is the ground for the thing. Similarly, expression is derived from expressiveness, and expressiveness gives quality to expression.

In a work of art we find analogues of emotional expression. In life we can express emotions by means of gestures, postures, facial expressions. Through interpretation of life we can look into the meaning of emotional expressions. Representational paintings and sculptures can usually express emotions by depicting people who are expressing their emotions in facial expressions, postures, gestures, and actions. We can express emotions by describing or representing a point of view (Robinson, 2007: pp. 21-22). Artists can express their emotions not only by the way they depict a scene but also by the way they manipulate their media. We interpret the depicted characters as expressing their emotions. The kernel of the idea of emotional expression in ordinary life persists in emotional expression in the arts. Expressions are means of communicating emotions to others. Expressiveness is a cognitive notion of knowing the inner world. Expressions reveal something about the nature of the emotion expressed. Emotional reactions to expressive emotional expressions do not always reflect the emotion expressed (Robinson, 2007: pp. 28-31).

Expressive qualities can reveal what is expressed. If we think of expressiveness as a matter of how clearly the emotion expressed is revealed in the expression, then even inexpressive expressions are to some small degree expressive. Dynamic structures and configurations of human behavior are associated with the expression of emotion. How to experience the object is involved in the expression of emotion. Distancing attitudes of artistic appreciation as beholder is the representation of the object in art. It is necessary for empathic communication. Aesthetic appreciation can be modified by integrating our concern with geologic appearances. According to expression theory, emotion in artwork is, ideally, the same as the emotion of artist. Expressive qualities are communicative among others. The forms of human feeling like anger, calmness, sadness, etc. can be more congruent with forms of natural phenomena like seabed or rock formation. "The forms of human feeling are more congruent with musical forms than with the forms of language, music can reveal the nature of feelings with a detail and truth language cannot approach” (Langer, 1942: p. 235). Whether expressive qualities can be fine-grained or coarse-grained, they can often be beyond conceptuality. In the event of pure instrumental music, expressive qualities can be found among qualified listeners with delicacy. "Pure instrumental music cannot represent the cognitive components of many emotions" (Spackman, 2012: p. 305). Cognitive components of emotions are

\footnotetext{
${ }^{4}$ Although R. G. Collingwood said art is the expression of emotion, according to different positions like realists, formalists, conceptualists, and minimalists etc., this statement may be accepted differently.
} 
congruent with knowing-function instead of showing-function.

Structural similarities between emotion and its representation are not cognitive, however but analogous. "To experience an expressive quality involves exercising a certain imaginative capacity” (Spackman, 2012: p. 306). Earth like music can be expressive of fine-grained emotions. Experience of an expressive quality is involved in exercising a certain imaginative capacity. In other words, to experience an expressive quality is equal to experiencing an imaginative mode of perceiving the object. The account of ascriptions of expressiveness has more specific potentiality than any description comprised of emotional terms. We cannot claim that "expressive qualities are uniquely fine-grained and every artwork expresses a different emotion” (Spackman, 2012: p. 308). Expressive qualities can be beyond effability or in the limits of effability, but they can remain descriptively ineffable. Expressive qualities are not strictly ineffable since they can be grasped by demonstratives.

Here we have to consider the peculiar function of emotion. In the perspective of "deeper than reason" (Robinson, 2005). Jenefer Robinson argues the role of emotion in literature, music, and art. It means the existence of deeper parts of our minds or inner world which we cannot reach with the capacity of reason. So she calls it "deeper than reason". It recalls to us the function of emotion as analogonrationis (the analogy of reason) in context of A. G. Baumgarten (1714-1762). Every artistic object is filled with sources for the expressive qualities or expressiveness. Through interpretation we can approach the deeper part of our emotions and depth of emotional expression. Various changes of earth present emotional characteristics in appearance. It does not obviously explain those cases of apprehension of a more perceptual nature as when we hear or see emotion in the object. "To settle what expressiveness in an artwork is, we still need to go on to decide when a work expresses emotions we perceive or infer in them, i.e., when it is correct to attribute the state to the work” (Stecker, 2001: p. 89).

Expressiveness is combined with the features in a work of art and linked ultimately to the states of feeling or emotion. The emotion of the subject depends on the expressiveness of the object. Problems of expressiveness have been most frequently debated in connection with music (Osborne, 1982: pp. 19-26). A good reason for this does not lie in expression, but in expressiveness. Symbolic and metaphoric meaning of expression is contained in expressiveness. Representational works of art portray emotional situations and their nonrepresentational features contribute to the emotional impact. Expressiveness is more significantly discussed in nonrepresentational features in representational works of art. Non representational is related to a style of art in which natural objects are not represented realistically.

"A piece of music is not sad because it can be used to evoke sadness, or noble because it can be used to create an atmosphere of authority" (Scruton, 1974: p. 28). The sounds of music are not sad, they just evoke or create some specific emotional feelings. Likewise, the features or figures of the earth's surface are not emotional, they just evoke or create some specific emotional feelings. In the musical sounds, it is not a problem of intellectual apprehension and information, but a problem of emotional response and communication to share common sense that is important. "The function of music is not stimulation of feeling, but expressing of it; and furthermore not the symptomatic expression of feelings that beset the composer but a symbolic expression of the forms of sentience as he understands them” (Langer, 1953; Osborne, 1982: p. 20). Feeling is in some way embodied in the work of art, and in the perception of the work we perceive the embodied feeling. There is an important phenomenological difference between the feeling tone incorporated in emotional response and the embodied feelings we perceive in works of art. The feelings we perceive in works of art are permeated phenomenologically into the works. Emotional expression is the revelation of the concealed or the hidden core.

What expression can actually reflect is only the form and structure of feeling. Expression is the analogue of emotive life. "An emotion cannot be felt without being expressed" (Collingwood, 1958: p. 238). So we can feel an emotion through the expressive process. Expressiveness focuses on resemblances between appearance and the characteristic, gestural expression of feelings. Natural expressiveness of human behavior is similar to expressive qualities of movement. There are structural similarities between musical patterns and the patterns of spontaneous human gesture (Osborne, 1982: p. 23). There will be similarities between geological patterns and the patterns of human feeling. For example, a steep cliff and slopes are often represented as a symbol of despair, or in poetic expression we can feel deep solitude from a cliff.

The artworld contains a great deal of self-expression, namely the artist's own self-expression. Mitchell Green explains expressiveness as a matter of an object's making available certain types of knowledge, most notably, qualitative knowledge concerning how an emotion or other experience feels. The expressiveness we see in things is a static state in the object, whereas, expression is the dynamic process of the expresser. Static expressiveness serves as a potential energy for dynamic expression. I think the source of expression is self-expression 
because self-expression is related to introspection and self revelation. "In self-expression we show what's within. In certain cases we show what's within by showing that things are thus and so within us; in other cases we show what's within by making some aspect of what's within literally perceptible” (Green, 2007: pp. 171-172).

Expression is a matter of showing what is within. And self-expression is showing how one feels. "Sensory experience typically gives us both knowledge-that and knowledge-how. Knowledge of how something looks, sounds, tastes, and so on, seems to equip us with a skill” (Green, 2007: p. 174). This skill is well applied to the training of empathic process. "Expressiveness may be found in objects that are not representational, as well as in objects whose representational character has nothing to do with their expressiveness" (Green, 2007: p. 193). The majority of theories of expressiveness in non-representational arts are primarily concerned with music. Non-representation in music is deeply seated in the inner part of representation.

We cannot speak of expressiveness in a fictional sense. But a fictional character can feel by imaginatively projecting oneself into the character's situation (Currie, 1998: p. 172). Some people can "identify expressiveness with the expression of a fictional persona. Classical expression theorists like Tolstoy and Collingwood would identify expressiveness with the expression of an artist." Those who understand expressiveness in terms of the possession of "emotion characteristic in appearance" identify being expressive of sadness with being sad (Stecker, 2001: p. 94, footnote 1). Robert Stecker used "expressive” and "expression” without distinguishing between them. But, I think, in the perspective of the subject-object relationship it needs to be distinguished. As the author referred to previously, "expressive" qualities are contained in the object, and "expression" is the activity of subject. "To say a work expresses an emotion can mean either that it is expressive of or that it is an expression of the emotion" (Stecker, 2001: p. 85). Expressiveness is concerned with the apprehension of an emotional state. An emotional state in appearance can have static or dynamic qualities. But "emotion is not a thing or a disposition: it is a process or sequence of events” (Robinson, 2005: p. 59).

\subsection{The Role of Empathy in Expressiveness}

We can read expressive qualities directly through formal features of an artwork. We have to figure out some kind of role for the expresser at the same time. For this we need to consider empathy. Empathy literally means in-feeling or feeling-into. According to German philosopher and psychologist Robert Vischer (1847-1933), empathy is to place human feelings into inanimate things, plants, animals, or other humans in a specific way. Empathy fuses a human's experience with an object's experience such that it no longer feels like the human's own experience but instead like that of the object. Theodore Lipps (1851-1914) promoted and elaborated the idea of empathy. In his aesthetic psychology, he used the notion of empathyto explain "not only how people experience inanimate objects, but also how they understand the mental states of other people” (Montag, 2008: p. 126). Experimental psychologist E. B. Tichener (1867-1927) defined empathyas "the process of humanizing objects, of feeling ourselves or reading ourselves into them” (Depew, 2005: p. 101). Empathy can be objectified into or projected onto every sort of object, whether it is inanimate or animate. For example, we can experience aesthetically the joyous chirping of birds, the sadness of the sagging willow tree, the sublimity of the starry night (Depew, 2005: p. 102). Through empathy we bring our animate feelings into inanimate things. Our aesthetic experiences place our feelings into things, as simulation theory claims, we do so by imaginatively putting ourselves in the other's situation ${ }^{5}$. So, then, these things become similar to something of our interior emotional feelings.

Empathy is a kind of imagining. The experience of an inanimate object arose from the empathy. In the perspective of the relationship between the observer and the observed, empathy projects the feelings of the observer into the observed. To read the expressed emotion from the description of the formal quality of artwork makes it possible to relate the inner and outer parts of the work. Here empathy plays a role in connecting between the inner and outer parts of the work. In many cases this connection seems to be communicative between the real and the unreal in the form of as-if ${ }^{6}$. The epistemic value of artworks lies in knowing the unknown world. Artistic expression and expressiveness make it possible to have aesthetic reconstruction of the world. Empathy plays a

\footnotetext{
${ }^{5}$ Margrethe Bruun Vaage, 2009: p. 109, "The Role of Empathy in Gregory Currie’s Philosophy of Film”, British Journal of Aesthetics, Vol.49 N0 2, April. She defines simulation as imaginative engagement in another person's experiential perspective. Empathy is to simulate the situation of the character, imagining being in his situation.

${ }^{6}$ The philosophy of as-if is introduced by the German philosopher, Hans Vaihinger, through his book in the year of 1911. Based on I. Kant and F. Nietzsche, he holds the compatibility between the reality of sensations and the imaginative fiction of human knowledge to be justified pragmatically.
} 
role in opening the unknown world. "Showing-how can provide qualitative knowledge for those with appropriate sensory capacities. It can also enable empathy for those with the capacity for empathy” (Green, 2008: p. 97). Showing how and knowing how are related to each other. Qualitative knowledge can be obtained by appropriate sensory capacities. Know-how is often only possible with some practice, that is to say, perceptual experience (Green, 2008: pp. 98-99).

Perceiving aspects and affects in a painting or drawing shows some aspect of what it represents. M. Green asserts that there will be a reliable causal connection between the thing represented and the pictorial representation itself (Green, 2008: p. 103). But, the author thinks, here, not the causal connection but the imaginative mode of perception plays a linking role between the thing represented and the pictorial representation itself. The thing expressed and the pictorial expression itself are related to each other in an imaginative mode of perception. One needs to be careful about T.S. Eliot's notion of an "objective correlative” of emotion. "The only way of expressing emotion in the form of art is by finding an 'objective correlative'; in other words, a set of objects, a situation, a chain of events which shall be the formula of that particular emotion; such that when the external facts, which must terminate in sensory experience, are given, the emotion is immediately evoked... The artistic 'inevitability' lies in this complete adequacy of the external to the emotion; and this is precisely what is deficient in Hamlet” (Eliot, 1921; Green, 2008: p. 110). Eliot takes the only way of expressing emotion in the form of an "objective correlative". The author thinks this "objective correlative" is an interchangeable term with structural similarity. Anyway, because of this "objective correlative", expressing emotion can have validity between subject and object.

"One would expect that knowing how an emotion or experience feels enables me to 'feel with' someone who is actually in the grip of that emotion or experience. Artworks that are expressive by virtue of showing how an emotion or experience feels enables me to empathize with others" (Green, 2008: p. 110). There is a delicate difference between sympathy and empathy. Sympathy seems to involve taking a concern for the well being of another, and sharing a common sense or perceptual experience with each other. On the contrary, "empathy requires one imaginatively to enter into a character's mind and feel with him because of one's imagining of his situation." ${ }^{7}$ If we take a concern for something, then we can easily enter into something.

Empathy is the ability to identify and understand another's situation ${ }^{8}$. Is it possible to cultivate empathy? According to M. Green, empathy involves the exercise of a skill. "The artwork might show how that emotion feels by exploiting congruences between sensation and affect. Such an artwork can show how an emotion feels without being representational. A non-representational painting might be congruent with central aspects of exuberance” (Green, 2008: p. 115). For example, Mark Rothko's color field paintings are commonly thought to be about the expression of emotion, and they are distinctly nonrepresentational. A work of art might also exploit the power of representation to show how an emotion feels. A work of art can show me how an emotion or mood feels. A work of art can reacquaint me with an emotion or mood by bringing it to aesthetic consciousness. Further, a work of art can show me how an emotion or mood feels without causing me to feel that emotion (Green, 2008: p. 116). What's the role of consciousness in emotional feeling? According to M. Green, it might do that either by engaging the imagination, or by exploiting our sensitivity to congruence between experiences, on the one hand, and emotions and moods on the other. Expressiveness and empathy are, then, closely linked. Something that is expressive of an emotion, mood, or experience shows how that emotion, mood, or experience appears or feels (Green, 2008: p. 117). Through empathy we can know the expressiveness which is hidden deeply in the object, so we need empathic experience for that. It deepens the contents of experience in others.

"While expressiveness in the service of empathy is not the exclusive domain of art, and while a great deal of art aims at nothing of the kind, it nevertheless appears that one central function of art forms as disparate as painting, music, literature, film, and photography is that they show how emotions and moods feel in such a way as to equip us to achieve a greater rapport with others... Art's emotion is a reflective, thought-provoking exploration of the significance that experiencing emotion through art has upon our lives” (Green, 2008: p. 118). Triad relations of expressiveness, empathy, and experience take place intensely in the emotional response to natural landscapes as well as in art's emotional content which are based on our lives.

Here we can raise the question of what the function or role of empathy in expressiveness and self-expression is. "Showing how an emotion, mood, or experience feels might enable you to empathize with me" (Green, 2007:

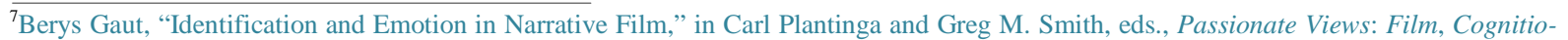
nand Emotion, Baltimore, MD: Johns Hopkins Univ. Press, 1999: p. 206, and Mitchell Green, 2008: p. 113.

${ }^{8}$ In management, empathy skill is known as a learning process how to better manage, motivate and transform the performance.
} 
p. 189). The possibility of empathy depends on showing how to feel emotion, mood, or experience. Green explains this well in Rodchenko's photograph, Pioneer Girl (Gelatin silver print, 49.637 cm, 1930, The Museum of Modern Art, NY). It gives us the feeling of admiration, "not because it bears a perceptual resemblance to literal expressions of admiration, but because it enables us to know how admiration feels” (Green, 2007: p. 199). Instead of perceptual resemblance empathy might be due to knowing how to feel. In Rodchenko's Pioneer Girl we watch her defiant, unblinking, and proletarian eyes. We feel admiration not on behalf of perceptual resemblance, but on behalf of empathy. In other words, the background of admiration is empathy.

\section{Expressiveness as a Possibility of Aesthetic Expression in Geoaesthetics}

The expressiveness of the features of the earth is a means to explain how the earth possesses the features that give rise to the desirable relationship between the earth and humans. The earth has many qualities that can be appreciated aesthetically. The beauty of landscapes as natural beauty shows us one of its most common aesthetic expressions. This beauty of natural landscapes is related to the subtle changes in the earth's surface. This surface is a result of geologic transformation. Geoaesthetics as an aesthetic inquiry into the beauty of geological phenomena has the task to search for expressiveness and the intention of the aesthetic expression. The search for expressiveness can connect expression and expressed. The contents of geoaesthetics comprise the expressiveness of rocks, formations, minerals, natural monuments, outcropings, and structures, as well as typical geological phenomena. The expressiveness of rocks or metals used in decoration, architecture, and land art or earth art activates the aesthetic imagination.

Geological phenomena are full of sources of aesthetic expressiveness. Various features of geological structures can be found in earth surfaces in forms of earthsong, geologically dramatic phenomena, and earthworks however we may name them. The emotions we experience in geological phenomena are not the same as the emotions of everyday life, but basic dimensions of feeling made determinate and precise by the geological content. The expressive character of geological appearances emerges sometimes with figurative composition. In the progression of earthly changes, all moments of the changes are full of expressiveness. It is important for the aesthetician to find a specific expression from them. We can observe expressiveness in the earth's faces which are characterized by geological changes.

Viewed in terms of a subject-object relationship, expressiveness is oriented toward the side of the object. Life, the arts, and natural phenomena are connected and inter-dependent with each other. Emotions in life are expressed in the arts. Artistic expression seeks sources from the expressiveness of natural phenomena. Systems of natural circulation include tornadoes, other weather systems, and ocean currents. Discovery of expressiveness in nature, and geological phenomena will be made through changes from inside of the earth outwardly. Expressiveness in geological phenomena has the double aspects of rest amidst motion, and motion amidst rest.

The elements of expression and expressiveness are extended from ordinary life in the arts, to geological phenomena. My purpose here is to expose the expressiveness in natural, geological phenomena. "Artistic expression has the same basic structure and function as expression in ordinary life... and an expression of emotion in art is just like an expression of emotion in life" (Robinson, 2007: pp. 19-20). Geological phenomena as objects of artistic expression can be in many cases like the spontaneous overflow of powerful, vital feelings. How can feeling be embodied in earthworks? The art of altering the natural environment creates earthworks. Sculptural forms of earth, rocks or sometimes plants are good material for artistic expression. But there can be a difference between emotional response and perceived feeling. Through empathy this difference can be resolved.

The feelings we can experience in geological phenomena and the feelings we experience in ourselves are accessible with directness and vividness. To this point we hear the expressiveness of music, "the natural patterns of expression are simply too vague to account for the vividness of the feelings we experience in music" (Osborne, 1982: p. 24). To experience this directness and vividness we need to empathize with others. As shown in Earthsong (N.Y.: Phaidon, 2008) by Bernhard Edmaier and Angelika Jung-Hüttl, music and geological phenomena are quite similar in experiencing expressiveness. The natural patterns of expression are often too broad and vague to explain the direct vividness we experience in geological phenomena. Phenomenologically, our perception of feeling in music and the abstract arts is direct, more like our awareness of our own feelings than our inferences about the feelings of other people from their bodily movements, which the movements of music are said to resemble. The emotional center of perception presents the natural world as being a certain way for the emotional response. 
Nature draws lines and forms shapes by itself. Tidal currents flow in natural rhythm. Countless streams of melt water flow seaward from inland glaciers in the wider riverbed. Sandy beaches, seabeds, and rock formations are accentuated at the peak of change in the scenery of nature. "As sea water freezes, frazil ice forms, when the wind and the waves bring the surface into motion, this freshly frozen but elastic covering shatters into a mosaic or countless ice floes” (Edmaier \& Angelika Jung-Hüttl, 2008: p. 76). The land around an Icelandic glacier shows how ice can deform, transform, and reform the ground and give us the figurative line and shape. "After a few initial spurts of ash, the lava began to flow quietly from a series of craters" (Edmaier \& Angelika Jung-Hüttl, 2008: p. 94). Lava as molten rock expelled by a volcano assumes the form of the various figures during an eruption after solidification and cooling. "Waves washed it shore, where the wind blew it deep inland, shaping the sand hills" (Edmaier \& Angelika Jung-Hüttl, 2008: p. 154). Waves play an important role in keeping the balance in natural circulation. Natural harmony and equilibrium are the beginnings of our existence.

Even if we can use emotional expression in the combined terms of emotion and expression, expressive qualities are distinguished from emotional qualities of artworks on the basis of their representational properties (Spackman, 2012: p. 303). In relation to the possibility of conceptualization we can consider expressiveness in the arts, as the expressiveness lying at the margin of conceptualization. The author thinks, one of the important tasks for the artist is to find and draw out expressiveness from the object with his capacity for emotional expression. Nature as a treasure of biodiversities has different expressiveness. Imagination transforms the inanimate object of nature into the animate object. Expressive qualities and imagination have common ground in natural figures.

The rocks have weathered into various shapes. A weathered rock is capable of expressing emotions. It may be involved in various forms of aesthetic appreciation. Henry S. Moore (1898-1986), an English sculptor and artist, is best known for his semi-abstract monumental bronze sculptures. His forms in Double Oval (1966), Oval with Points (1968-1970) are pierced or contain hollow spaces. Many interpreters comparing figuratively, liken the undulating expressive form of his reclining figures to the landscape and hills of his birthplace. Holes in rock and arches shaped by weathering and erosion have an influence on the expression of Henry Moore's sculpture. Through the empathic imagination of an artist, the geological phenomena of sand, soil, seawater etc., can be shaped into various figures which are full of expressiveness.

If we consider the expressiveness of natural figures related to the origin of place names, we can realize the wonderful correspondences of figure and expression like the names of living organisms. As one of these examples, Eagle Rock is an area of L.A. and derives its name from a massive boulder, similar to the figure of an eagle in flight. It's a good example of the expressive quality of a rock as an inanimate object, restored to an eagle as an animate object. Expressive qualities are descriptively effable. Emotional qualities might be attributed to works of art on the basis of their representational properties. Expressive qualities are emotive qualities that works possess in virtue of their possessing certain formal, non representational properties.

According to M. Green, self-expression is a pervasive phenomenon of the everyday life of humans and other species. He explores the ways in which self-expression reveals our states of thought, feeling, and experience. Self-expression is a matter of showing a cognitive, affective, or qualitative state. Aesthetic appreciation can be modified by integrating our concern with the phenomena. Susan Langer talks about expressiveness. We can reveal expressiveness by using forms. Here, the term "form" can mean the color, shape, or lines of a work. These forms aren't specific to visual art. Art expresses a feeling, and that feeling can be anything like touchness, emotion, even a pattern of ideas. Langer only believes that art must express something. The idea of a dynamic form was interesting because of its specificity. Form, in this context especially, is a specialized idea. For example, tragic emotions are necessary in order to write a tragedy. But, if you aren't feeling what you're expressing, you aren't expressing at all (Dayton (ed.), 2011: pp. 168-173). Sincere expression grows out of true feeling and emotion.

A sense of season or seasonal change of climate, because of extreme or violent climatic changes, has recently become closely related with geological turns. "The sense of melancholy or resignation becomes an object of aesthetic contemplation through the natural phenomena like snow, rain, wind, cloud, etc.” (Saito, 2005: p. 167). Perceptual representations of geological phenomena is to perceive the expressiveness of an object. One must perceive it as anything other than what it is. The aesthetic experience of natural objects and phenomena is found in the hidden expressiveness beneath them. Land art or earth art derives part of its aesthetic appeal from its transient nature (Saito, 2005: p. 171). Above all land art or earth art is characterized by nature itself.

The forms and media of art can be different, but the expressiveness which is contained in objects can be the 
same. In various genres of art like sculpture, drawing, relief, all-over painting, collage, terra cotta, installation, even petroglyph, their expressiveness is linked to the emotion of human beings. Various earth changes are analogous to mental and physical changes. Expressiveness in art mirrors expressiveness in life (Robinson, 2007: p. 32). It is applied to natural phenomena. "A windswept cliff might look melancholy, yet we are not about to attribute feelings to cliffs” (Green, 2007: p. 40). Perhaps all aesthetic expressiveness may ultimately be traced back to expression of artwork.

\section{Geoaesthetical Expressiveness in Geological Phenomena}

Natural order encompasses the natural relations of beings to one another. Especially in this time of global warming and climate change we are facing incessant geological changes like volcanoes, earthquakes, tsunamis besides human activities such as the burning of fossil fuels and deforestation. To consider the aesthetic expressiveness in geological phenomena one needs to link art and geology. In the relation of seeing art and nature we can confirm that color, line, pattern, and texture are the main expressive elements of geological surfaces like deserts, lava flows, canyons, etc. (Abbey \&William Fiero, 1986).

\subsection{Natural Order and Equilibrium in Geoaesthetical Expressiveness}

There are infinite, conflicting forces in nature. All natural forces in natural eco-system are trying to keep in balance with each other. "The general equilibrium which reigns amongst disturbances and apparent turmoil, is the result of infinite number of mechanical forces and chemical attractions balancing each other out” (Jardine, Secord, \& Spary, 1996: p. 290). The physical universe is considered as an orderly system subject to natural laws. In a word, it intends cosmos in chaos. "As in all other phenomena of the physical universe, so in the distribution of organic beings: amidst the apparent disorder which seems to result from the influence of a multitude of local causes, the unchanging law of nature become evident as soon as one surveys an extensive territory, or uses a mass of facts in which the partial disturbances compensate one another” (Jardine, Secord, \& Spary, 1996: p. 298).

We can raise the question of what the ultimate purpose of natural changes or geological transformations is. Geological phenomena will be brought into equilibrium after incessant changes and transformations. James Turrell (1943-), an American artist of light and space, has been sculpting a natural volcanic site, Roden Crater (1977, located outside Flagstaff, Arizona) into a place to space out. He regards the site of the earthwork very highly and uses light as creative media. Spatial installations in the sky, projects of land art, architectural lighting, etc., as site specific arts are possible only on behalf of physical, natural surroundings. It aims at contemplation and makes us think about our status in nature.

Bernhard Edmaier and Angelika Jung-Hüttl show us in their book Earthsong, earth's surface and natural landscape. Earthsong reveals areas almost all around the world. It shows us boundless beauty through patterns of the earth's surface during geological processes. The constant alteration of frost and thaw are intended to reach equilibrium in the end. "The top layer constantly solidifies and liquefies keep the balance... The land around an Icelandic glacier shows how ice can deform the ground and give us the figurative line” (Edmaier \& Angelika Jung-Hüttel, 2008: p. 80). Even deformation, transformation and alteration of forms or shapes are aimed at ecological balance. Natural phenomena such as volcanoes, glaciers, coral reefs, canyons, sea beds, and rivers reveal the delicate and monumental natural patterns that are etched on the earth's crust.

Biodiversity harmonizes with the ecosystem in natural order. Natural phenomena dominate and define the landscape. Tidal currents and waves are flowing in rhythm with tidal power. Waves and winds shape beautifully and dynamically the margin between sea and earth. Many melt water streams flow and form beautiful watery landscapes. Geologic features and landscapes are represented throughout the spectacular examples of mountain peaks, coastal cliffs, headlands, beaches and sand dunes, desert surfaces and canyons, and unique physical environments, such as caves, lava fields, and tufa structures. In addition to providing beautiful landscapes on macro as well as micro scales, it maintains order in disorder.

For example, Lemnos is a volcanic island of Greece in the northern part of the Aegean Sea. It is composed of rare geological and rocky formations, but also of rich ecosystems. Spectacular formations of fine sand form a unique and fascinating landscape. An area of natural beauty is characterized by great volcanic formations, picturesque coves and strange rock shapes. If we find some expressive qualities in geological phenomena and figures, then we realize these phenomena or figures are full of expressiveness. We find order in irregular and con- 
fused processes as a result of observing the inner part of the earth. The inner and outer cores of the earth are the origin of force which cause massive geological events such as crustal movements of earthquakes and volcanoes, etc.

The geologic world contains a great deal of expressiveness which can have influence on our emotional feelings. It can be characterized as earth song, and the face of earth, similar to music, and the human face. Like our facial expressions we can read a sad look in a sad face, an angry look in an angry face. There is no distance between feeling and revelation. An object's expressiveness derives from the artist's ability to show his own self-expression. Expressiveness can be linked to self-expression. As H. Osborne suggested, to understand the emotional feeling in music gives us the comparative point. "The natural response to feeling in music is a 'mirror' reaction. In this respect expressive musical sound differs fundamentally from the feelings we attribute to other people by inference from their behavior and is similar in its operation to the other fine arts, particularly dance. A theory which pivots on supposed resemblances between musical structures and characteristic patterns of feeling must obviously stand or fall by the corrections of the picture which it offers of these 'natural' expressive patterns. The gestures, deportment, movement, and postures of the body are indeed, outside language, the ultimate source of all communication of feeling and emotion among me" (Osborne, 1982: p. 23). Aesthetic consciousness of the subject moves toward the object, here intentionality is the mind's capacity to be aimed at something beyond itself. The feeling body is taking part in a world of directed activity. Feeling and mood are vague and formless states of being, lacking shape or structure, though while it lasts a mood colors one's whole outlook on life.

The feelings we perceive in art are similar to the emotions we experience in life. Non-representational art cannot express emotion but in expressing the affective constituent of emotion it sharpens it to a different kind of vehicle and content of feeling. The feelings in non-representational art are the same as the feelings in life, but they can be "objectless" feelings. The content of life's emotions cannot be exactly expressed in nonrepresentational art. Instead, the feelings are expressed and given to a new content of life, which is the abstract structure that bears them (Osborne, 1982: p. 25). The feelings in geological phenomena are similar to the feelings in non-representational works of art, but they are "objectless" feelings. To draw analogies between the structures of object and the content of life-emotion is not easy. Further, to seek resemblances between geological patterns and emotional expressions in life is important. The problem is not drawing analogies, but making analogies between them. Expressiveness is a new and more specific content. There are some resemblances in "the emotive expressiveness of tonality. The way major chords, minor chords, and diminished chords are heard respectively as cheerful, melancholic, and anguished” (Green, 2007: p. 179). These metaphorical, emotional expressions can be contained in the geological face of the earth. It matters how to find out resemblances between them.

Self-expression is related to self-revelation. In this climax of self-expression and self-revelation we can enjoy the sublime. According to Mitchell Green, "self-expression is bound up with communication” (Green, 2007: p. 4). In ths case commiunication is a matter of successful signaling and sharing each other's feeling, so to speak, mutual response. Sometimes we describe nature's face as expressive. So that inanimate objects can be transformed into animate living organisms, being expressive with feelings, moods, and thoughts. What is revealed in self-expression can be known by introspection. The epistemic value of art is deeper than reason and how to know, and at the same time, deeper than emotion and how to feel. In this context we can say that self-expression is concealed beneath the expressiveness.

Expressive appearances are attributed to the properties of the things. The inner expressiveness of things resembles the dynamic character between things and human movement. The degree of similarity between expressive appearances and human appearances depends on aesthetic experience. How much similarity is required to make for expressiveness? To explain the degree of similarity we must go the way of Jerry Levinson's persona theory. According to persona theory, if an object has affective quality, then imagination of an object contains affective quality of expression. Hearing expressiveness in music commits us to hearing it as, or to being disposed to hear it as, an expression of emotion by what Levinson calls a "persona” (Green, 2007: pp. 202-203).

We should not consider emotion in geological appearances, but a perceptual quality associated with emotion. A work of art can show the intensity and degree of a perceptual quality associated with emotional feeling. This emotional feeling can be either familiar or unfamiliar. Something that is expressive of an emotion or experience shows how that emotion or experience appears or feels (Green, 2007: p. 211). Through empathy we can find the aesthetic expressiveness which is deeply rooted in the object. Empathy plays a role in signaling and canalling expression to expressiveness. In the phenomenology of emotion this feeling is the foundation of aesthetic con- 
sciousness.

\subsection{Aesthetic Expressiveness in Geological Phenomena}

If we observe the earth from the environmental satellites in orbit around the planet, we can watch the beautiful images of patterns, shapes, colors, and textures of the land, oceans, glacier, and atmosphere (Friedl, Karen et al., 2012). These show us impressive beautiful landscapes. These beautiful images are sometimes ineffable and nonconceptual. According to various expressions, we can experience that the beauty of earth ranges from the concrete to the abstract, and from the real to the surreal. In the end we can feel the sublime beauty of nature. Now we confirm and watch some leading features of these beautiful images.

As far as expressiveness is concerned, music, especially pure instrumental music is very similar to geological phenomena. It is clear "music itself is inanimate and does not possess emotions" (Trivedi, 2001: p. 411). Geological phenomena, like music, are inanimate and do not possess emotions. Movement essential to certain emotions like shaking or trembling in geological phenomena is intrinsic to acute agitation. The motive of inanimate objects is linked to animate objects. Geological phenomena are inanimate, but owing to expressiveness can be transformed into animate. Because of structural resemblances between expressing subject and expressed object we can feel something like animate in inanimate objects. We can say geological features are expressive, because these must be true to the various experiences of geoaesthetical expressiveness. "On behalf of lifelike, animate expressiveness thing can be alive and lie in psychological states” (Trivedi, 2001: p. 415). We make a thing itself believingly animate, even though we know the thing is inanimate. Earth itself is inanimate, but owing to its affluent expressiveness it can be animate, namely a living organism. In the following I will consider expressiveness in four areas from a geoaesthetical point of view ${ }^{9}$. The choice of four areas are more or less random and arbitrary, and also not so much natural as landsatellite images. Nevertheless, in terms of the aesthetic sense of the earth, in looking for expressiveness, their own unique and universal meanings can be found.

The Sustina glacier surface in the Alaska range appears especially complex, with contrasting patterns near the center of the image (Friedl \& Yuen et al., 2012: p. 124). Meltwater rushes, ice crawls, and glaciers flow downhill. Steep cliffs and slopes in the glacier surface or in tributary glaciers flow into the sea in a free and vivid formation. Glacial surges can occur when meltwater accumulates at the base of a tributary and lubricates the flow. The underlying bedrock can also contribute to glacier surges, with the movement of soft and easily deformed rock leading to more frequent surges. Because of infrared photography colors of images are not so clear, but like calligraphic work we can feel strong brush strokes full of vital life. This image is permeated with animation and vividness. Of course, the pattern of this image is full of flexible and dynamic expressiveness.

In the satellite image of Erg Chech located in western Algeria, amber and caramel lattices are composed of large, linear sand dunes like geometrical, abstract compositions (Friedl \& Yuen et al., 2012: p. 124). An Erg, meaning sand sea, sand sheet or dune field in Arabic, is a wide, flat area of desert covered with wind-blown sand and little vegetation cover. In this image of the Erg Chech, dune sea located in the Sahara region of western Algeria the dune fields are contrasted strikingly with each other. The dunes are formed when large amounts of transported sand are halted by topographic barriers. Strong winds in sandy regions of the Sahara sweep over the desert landscape and deform the total topographic patterns. As a result, in the dynamic composition we can see the solemnity of nature. It shows us the harmonious order and at the same time, the wonderful, marvelous beauty of the earth as if it were painted on the sand ${ }^{10}$.

The Rub' al Khali, located in the Arabian Peninsula, meaning empty quarter, is the largest sand desert in the world $^{11}$. From the name of Rub' al Khali we can feel strong contrast between emptiness and fullness. In recent trends of arts, fullness is intended to emptiness. There is archaeo-geological evidence of ancient lakes and wildlife. Fossils of cattle and hippos are abundant, as are flint weapons and tools. Additionally, space-based measurements uncovered evidence of ancient civilizations. Subsequent excavations uncovered a large, octagonal fortress and shards of ancient Greek, Roman, and Syrian pottery. Formative volume and molding shapes are excellent, and patterns are well composed. In the zoomed-in image dune field patterns and bedrock forms seem to be in dynamic movement toward a certain direction in an established harmony.

\footnotetext{
${ }^{9}$ The sources of these satellite images in four areas are borrowed from Lawrence Friedl, Karen Yuen (et.al.), Earth as Art, NASA Earth Science, 2012, cf. http://www.nasa.gov/pdf/703154main_earth_art-ebook.pdf

${ }^{10}$ Sand paintings have a long established cultural event prepared for ritual ceremony in the meaning of religion and cure.

${ }^{11}$ Lawrence Friedl, Karen Yuen (et al.), 2012: p. 112. It covers 650,000 square kilometers and encompasses most of the southern third of the Arabian Peninsula. The desert includes most of Saudi Arabia and parts of Oman, the United Arab Emirates, and Yemen.
} 
The Erongo massif is a prominent, sheer-walled semicircular mountain ${ }^{12}$. The mountain is covered with an eroded relic of a volcano that was active long ago but collapsed upon itself with the weight of the overlying magma. Eons of erosion by wind and wind-blown sand gradually exposed the long-dead volcano's core of granite and basalt. Minerals have been collected in the Erongo region, including some of the finest aquamarine, schorl, tourmaline, quartz, muscovite, hyalite, and jeremejevite. The area has a confluence of ecosystems that are home to a vast array of plant, reptile, mammal, and bird species, some endemic to Namibia. From an eroded relic of a volcano we can imagine various empathic feelings. The expressiveness in geoaesthetic context makes us experience the complex states of feelings like passion, fury, anger, even gloominess, etc. This area takes on an orange color at sunrise. In this moment we can feel the primitive stillness and tranquility of nature. This image is full of expressiveness.

\section{Conclusions}

The author has considered the meaning of expressiveness in connection to aesthetic expression and empathy. In geological phenomena the author finds natural order or equilibrium embedded in expressiveness. To find aesthetic expressiveness in nature it is useful to consider the harmonious coexistence between human beings and nature. The author made an attempt to get to the meaning of expressiveness in relation to geoaesthetics by revealing the expressive qualities through resemblances between the earth's surface and human emotional expressions. The author's interpretation can be called teleological in that it refers to equilibrium as the natural order through expressiveness. In addition, the expression of human emotions associated with artistic expressiveness and the expressiveness of natural phenomena seems to be anthropocentric interpretation.

Expressiveness has the quality of being expressive and serves to create expression. Expressiveness contains everything which can be expressed. Expressiveness is to be explained in terms of human emotional expression. So expressiveness is hidden beneath expression. Expression is oriented to the subject as an expresser, and on the other hand expressiveness is oriented to the object as a thing to be expressed. Expression can appear as the externalization of expressiveness after expressing activity. Expressiveness is grounded in a matter of either showing an emotion, mood, or experience, or showing how an emotion, mood, or experience feels.

The feelings we can experience in geological phenomena and the feelings we experience in ourselves are accessible with directness and vividness. This directness and vividness is only possible in living organisms. If we consider the expressiveness of natural figures related to the origin of place names, we can realize the wonderful correspondences of figure and expression similar to names of living organisms. The geologic world, as shown in the previous four areas, contains a great deal of expressiveness. It can be characterized as earth song, or earth face similar to sonic shapes, or human faces. Like our facial expressions we can read sad looks in a sad face, solitude in steep cliffs and slopes, or melancholy in willows, etc. There is no distance between feeling and revelation. "All expressiveness may ultimately be traced back to expression" (Green, 2007: p. 41). An object's expressiveness derives from the artist's ability to exhibit his own self expression. Expressiveness can be linked to self-expression.

Geological phenomena as the objects of expressiveness are inanimate, but owing to empathy these can be transformed into the animate expression. On the ground of structural resemblances between the expressing subject and expressed object we can bring validity or objective correlative. We can say geological features are expressive, and these must be true to the various experiences of geoaesthetical expressiveness. Earth itself is inanimate, but owing to its plentiful expressiveness it can restore the organic, animate world to life.

\section{References}

Abbey, R. D., \& William Fiero, G. (1986). Art and Geology-Expressive Aspects of the Desert. Layton, UT: Gibbs M. Smith, Inc.

Arnheim, R. (1949). The Priority of Expression. The Journal of Aesthetics and Art Criticism, 8, 2.

Arnheim, R. (1969). Art and Visual Perception. Berkeley, Los Angeles: University of California Press.

Collingwood, R. G. (1958). The Principles of Art. New York: Oxford U.P.

Currie, G. (1998). Realism of Character and the Value of Fiction. In J. Levinson (Ed.), Aesthetics and Ethics, Essays at the

\footnotetext{
${ }^{12}$ Lawrence Friedl, Karen Yuen (et al.), 2012: p. 44. Its diameter is $30 \mathrm{~km}$, and it rises $1200 \mathrm{~m}$ above arid Namibian plains to the west and a mixed woodland savannah to the east.
} 
Intersection, Cambridge: Cambridge U.P. http://dx.doi.org/10.1017/CBO9780511663888.006

Dayton, E., Ed. (2011). Expressiveness. Hertfordshire: Broadview Press.

Depew, D. (2005). Empathy, Psychology, and Aesthetics: Reflections on a Repair Concept. Poroi, 4, 1. http://dx.doi.org/10.13008/2151-2957.1033

Dilworth, J. (2004). Artistic Expression as Interpretation. British Journal of Aesthetics, 44, 10-28. http://dx.doi.org/10.1093/bjaesthetics/44.1.10

Eaton, M. M. (1988). Basic Issues in Aesthetics. Belmont, CA: Wadsworth Publishing Company.

Edmaier, B., \& Jung-Hüttl, A. (2008). Earthsong. NY: Phaidon.

Eliot, T. S. (1921). Hamlet and His Problems. In The Sacred Wood: Essays on Poetry and Criticism, London: Methuen.

Friedl, L., Karen, Y. et al. (2012). Earth as Art. Washington DC: NASA Earth Science. http://www.nasa.gov/pdf/703154main_earth_art-ebook.pdf

Gaut, B. (1999). Identification and Emotion in Narrative Film. In C. Plantinga, \& G. M. Smith (Eds.), Passionate Views: Film, Cognitionand Emotion. Baltimore, MD: Johns Hopkins Univ. Press.

Green, M. (2007). Self-Expression. Oxford: Clarendon Press.

Green, M. (2008). Emapthy, Expression, and What Artworks Have to Teach. In G. L. Hagberg (Ed.), Art and Ethical Criticism. Oxford: Blackwell Publishing Ltd.

Jardine, N., Secord, J. A., \& Spary, E. C. (1996). Cultures of Natural History. Cambridge, NY: Cambridge University Press.

Kivy, P. (2002). Introduction to a Philosophy of Music. Oxford: Oxford University Press.

Langer, S. K. (1942). Philosophy in a New Key: A Study in the Symbolism of Reason, Rite, and Art. Cambridge, MA: Harvard University Press.

Langer, S. K. (1953). Feeling and Form. New York: Charles Scribner's Sons.

Montag, C. (2008). Theodor Lipps and the Concept of Empathy: 1851-1914. American Journal of Psychiatry, 165, 1261. http://dx.doi.org/10.1176/appi.ajp.2008.07081283

Osborne, H. (1982). Expressiveness in the Arts. The Journal of Aesthetics and Art Criticism, 41, 19-26. http://dx.doi.org/10.2307/430820

Rader, M./Jessup, B. (1976). Art \& Human Values. Englewood Cliffs, NJ: Prentice-Hall.

Robinson, J. (2005). Deeper than Reason: Emotion and Its Role in Literature, Music, and Art. Oxford: Clarendon Press.

Robinson, J. (2007). Expression and Expressiveness in Art. Postgraduate Journal of Aesthetics, 4, No.2.

Saito, Y. (2005). The Aesthetics of Weather. In A. Light, \& J. M. Smith (Eds.), The Aesthetics of Everyday Life. New York: Columbia University Press.

Scruton, R. (1974). Art and Imagination. London: Methuen.

Spackman, J. (2012). Expressiveness, Ineffability, and Nonconceptuality. The Journal of Aesthetics and Art Criticism, 70, 303-314.

Stecker, R. (2001). Expressiveness and Expression in Music and Poetry. The Journal of Aesthetics and Art Criticism, 59, 8596. http://dx.doi.org/10.1111/0021-8529.00009

Trivedi, S. (2001). Expressiveness as a Property of the Music Itself. The Journal of Aesthetics and Art Criticism, 59, 411-420. http://dx.doi.org/10.1111/0021-8529.00042

Vaage, M. B. (2009). The Role of Empathy in Gregory Currie’s Philosophy of Film. British Journal of Aesthetics, 49, 109128. 
Scientific Research Publishing (SCIRP) is one of the largest Open Access journal publishers. It is currently publishing more than 200 open access, online, peer-reviewed journals covering a wide range of academic disciplines. SCIRP serves the worldwide academic communities and contributes to the progress and application of science with its publication.

Other selected journals from SCIRP are listed as below. Submit your manuscript to us via either submit@scirp.org or Online Submission Portal.
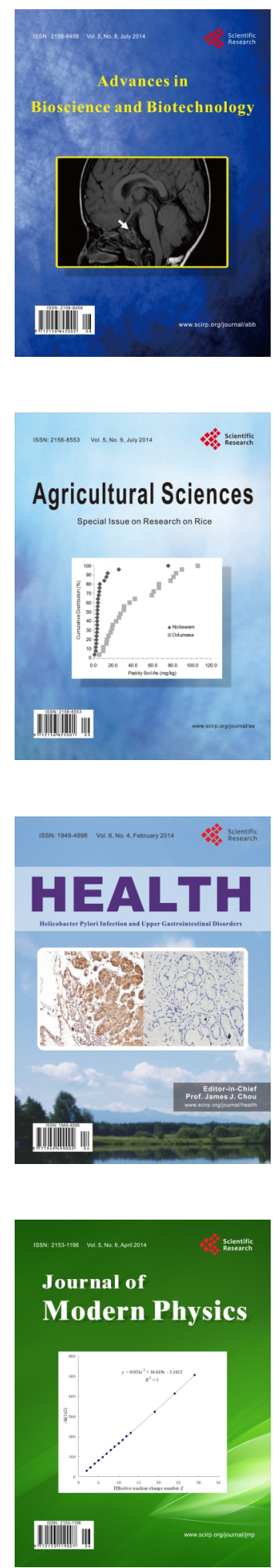
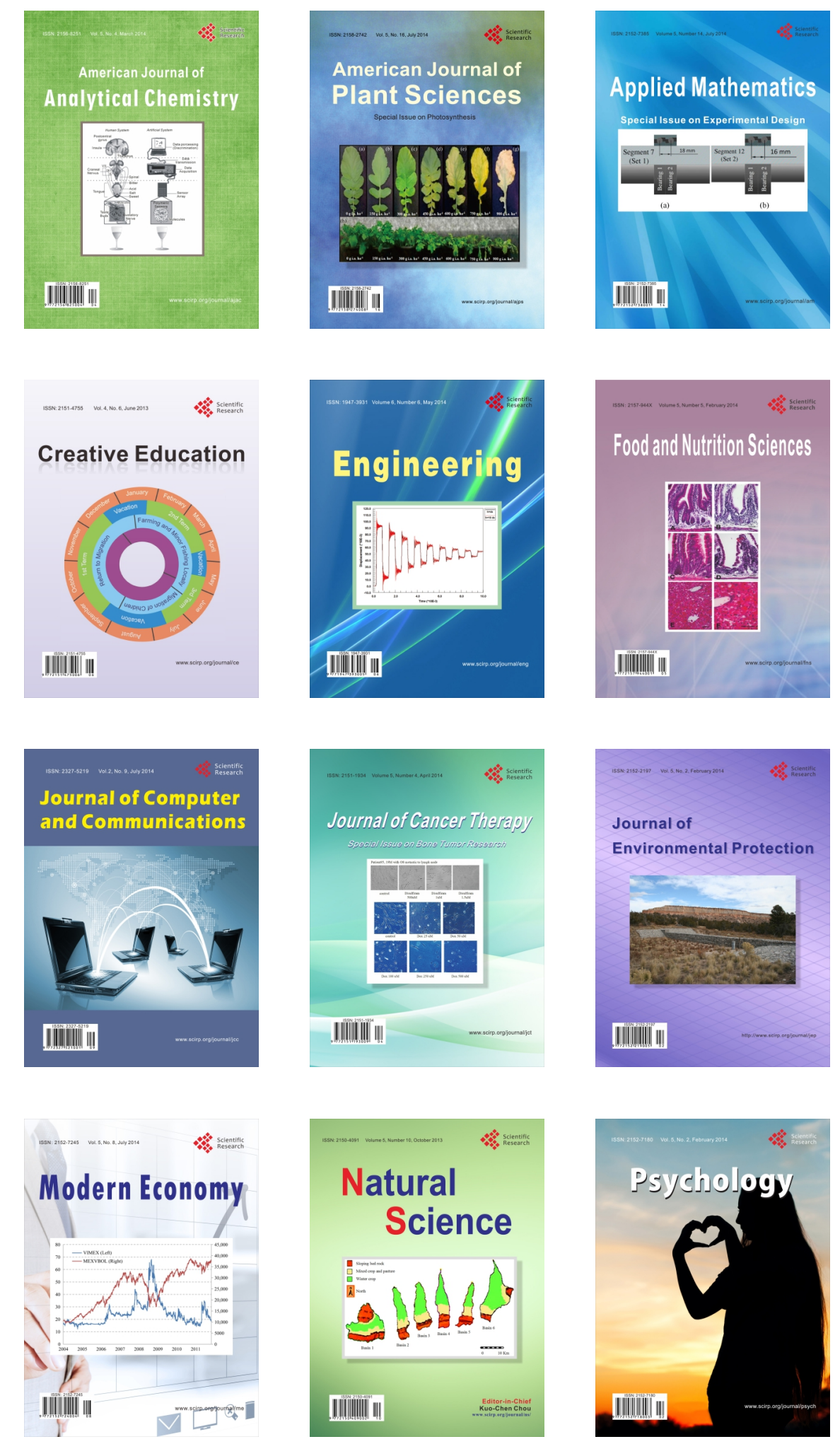